\title{
DRUG RESISTANCE TO ANTI-TUBERCULOTICS IN CHILDREN - THREE YEARS STATUS IN SLOVAKIA
}

\author{
Porvaznik $\mathrm{I}^{1,2}$, Mokry $\mathrm{J}^{2}$, Solovic $\mathrm{I}^{1}$ \\ ${ }^{1}$ National Institute of Tuberculosis, Lung Diseases and Thoracic Surgery, Vysne Hagy, ${ }^{2}$ Department of \\ Pharmacology, Jessenius Faculty of Medicine in Martin, Comenius University, Slovak Republic
}

\begin{abstract}
A b s t r a c t
Drug resistant tuberculosis is a serious and increasing problem worldwide, particularly in countries with a high incidence of tuberculosis and HIV infections. Resistant tuberculosis in children is usually due to the transmission of resistant strains from the environment where they live. Most often it is a transfer from the parents, or other relatives. A paucibacillary nature of the disease in children associated with difficulties in a collection of adequate sputum samples means that the samples are often microscopically negative. If the cultivation is negative, any bacteriological confirmation of the drug resistance is impossible.

The aim of this study was to review current diagnostic and therapeutic principles in tuberculosis in children and to demonstrate its incidence in population of the Slovak Republic during 2010-2012.

We have retrospectively analyzed all children sputum samples from children with diagnosed tuberculosis in Slovakia. The classical bacteriological analysis (culture on solid eggs-based media) was used to confirm the mycobacterium tuberculosis infection and the proportion method was applied to test its susceptibility or resistance to mostly used antituberculotics.

In years 2010-2012, three cases of resistant form of tuberculosis have been diagnosed in Slovakia among 16 children with cultivation positive to tuberculosis. In all of the cases the INH mono-resistance was confirmed (with the same strains present in their relatives), suggesting primary resistance origin of infection.

To ensure an appropriate and successful treatment of tuberculosis in children, accurate and timely diagnostics and determination of susceptibility to anti-tuberculotics is essential.
\end{abstract}

Keywords: tuberculosis, children, resistance, anti-tuberculotics, Slovakia

\section{INTRODUCTION}

Although tuberculosis (TB) belongs to the rare respiratory diseases in Slovak Republic (SR) and SR itself belongs to countries with low incidence of TB, the incidence in other (especially Eastern European) countries is still emerging (1). However, the mycobacterial strains resistant to various anti-tuberculotic drugs are emerging in the world. The former Soviet Union countries belong to areas where these strains appear very often. As immigrants often use Slovakia as a transit country, the problem of resistant TB strains may not be underestimated.

\section{Drug resistance to anti-tuberculotics}

The resistance of Mycobacterium tuberculosis (M. tuberculosis) to anti-tuberculotic drugs is mostly based on spontaneous genetic mutation superimposed by improper human policy. From the molecular-biological perspective, the resistance is based on gene mutations in mycobacteria, which frequently leads to a change in the target molecule associated with loosing the drug efficacy (2).

Traditionally, patients with drug-resistant tuberculosis (DR-TB) are classified into two major groups: 1) those who have acquired drug-resistant strain from community; 2) those where drug-resistant TB has been developed due to previous tuberculosis drug therapy.

Address for correspondence:

Assoc.Prof. Juraj Mokry, MD., PhD., Department of Pharmacology, Jessenius Faculty of Medicine, Comenius University, Sklabinska Str. N. 26, 03601 Martin, Slovakia

Phone: +421 43 2633619; e-mail: mokry@jfmed.uniba.sk 
Only the cases of primary drug resistance are assumed to be due to transmission of drugresistant strains (3). A person with fully susceptible TB may develop secondary (acquired) resistance during therapy (4). However, the clinical term "acquired" drug resistance should be replaced with the term "drug resistance in previously treated cases", which includes cases with drug resistance due to true acquisition as well as that due to transmitted drugresistant strains (3).

\section{Classification of drug resistance}

Generally, the resistance to anti-tuberculotic drugs in patients with TB can be classified as follows (5):

- Mono-resistance - resistance to one of first line drugs;

- Poly-resistance - resistance to two and more drugs;

- Multi-resistance - resistance at least to isoniazid and rifampicin;

- XDR - extensively drug-drug resistant - resistance at least to isoniazid and rifampicin and to any fluoroquinolone, and to any of the three second-line injectables (amikacin, capreomycin, and kanamycin).

The terms "extremely drug resistant" (“XXDR-TB”) and "totally drug-resistant TB" ("TDRTB") are used by the authors reporting on this group of patients (6). Nevertheless, "totally drug resistant" have not been yet clearly defined for tuberculosis. While the concept of "total drug resistance" is easily understood in general terms, in practice, in vitro drug susceptibility testing (DST) is technically challenging and limitations on the use of results remain (6). Conventional DST for the drugs that define MDR and XDR-TB has been thoroughly studied and consensus reached on appropriate methods, critical drug concentrations that define resistance, and reliability and reproducibility of testing. Data on the reproducibility and reliability of DST for the remaining second-line drugs are either much more limited or have not yet been established, or the methodology for testing does not exist. Most importantly, correlation of DST results with clinical response to treatment has not yet been adequately established. Thus, a strain of TB with in vitro DST results showing resistance could in fact, in the patient, be susceptible to these drugs. The prognostic relevance of in vitro resistance to drugs without an internationally accepted and standardized drug susceptibility test therefore remains unclear and current WHO recommendations advise against the use of these results to guide treatment (7).

\section{Diagnosis of DR-TB in children}

DR - TB should be suspected in children with active TB in following situations:

- A child, who is a close contact of an DR-TB patient,

- A child, who is a contact of a TB patient who died while on treatment when there are reasons to suspect that disease was DR-TB (i.e. deceased patient had been a contact of another DR - TB case, had poor adherence to treatment or had received more than two courses of anti-tuberculotics treatment),

- Children with bacteriological proof of TB who are not responding to first-line drugs given under direct observation (8).

The diagnosis of TB is more difficult in children than in adults. Symptoms of TB in young children can be nonspecific, e.g. chronic cough or wheeze, failure to thrive and recurrent fever (4). Bacteriological confirmation may be difficult to obtain because of the inability of children to generate a sputum sample, as well as the paucibacillary nature of pediatric TB and increased likelihood of extra-pulmonary TB in children (9). While every effort should be made to establish a bacteriological diagnosis and obtain drug susceptibility testing in a child with suspected DR-TB, in practice pediatric cases are often not confirmed bacteriologically (10). Use of scoring system that has been developed to aid screening and diagnosis of active TB is strongly recommended.

Children with DR - TB generally have primary resistance transmitted from an index case with DT - TB. Symptomatic pediatric household contacts should receive (10): 
- an evaluation by a physician, including history and physical examination;

- tuberculin skin testing (TST) with purified protein derivative;

- a chest X-ray examination (computerized tomography is helpful especially in documenting hilar adenopathy);

- a sputum smear, culture and DST. The bacteriological confirmation may include more aggressive measures such as induced sputum, gastric aspirate, lymph node aspirate or other relevant sample. Gastric aspirate should only be undertaken where culture facilities are available due to the low yield from microscopy and the distress involved for the children. Culture specimens need to be processed within the hour, because the acidic juices will kill the mycobacteria relatively quickly;

- HIV counseling and testing (in areas of high HIV prevalence or if parent(s) known, or suspected to be HIV infected).

When TST result is $>5 \mathrm{~mm}$ but chest radiograph and gastric aspirate or sputum smear are negative, the symptomatic child can be treated with a broad-spectrum antibiotics that is not active against TB, such as trimethoprim/sulfamethoxazole. The child should be followed closely, with evaluations including smear test and culture on samples from induced sputum or gastric aspirates, or sputum samples whenever is possible, as well as chest Xrays. The optimal frequency of these evaluations had not yet been determined. It is not clear whether the frequency of evaluation recommended for adults can be applied to children. If a child s clinical condition is highly suggestive of TB, or progressively deteriorates, empirical therapy designed according to the DTS pattern of the strain from the index case can be started (11).

\section{Treatment of DR-TB in children}

Treatment of children with DR-TB should be guided according to the DST results (in case of successful bacteriological evidence of disease). In case of absence of bacteriological confirmation, therapy should be based on the DST pattern of contact. If DST of contact is not available, therapy can be based on the common DST patterns of resistance in the community (12).

There is only limited experience with the use of second-line drugs for extended periods in children. The risk and benefits of each drug should be carefully considered in designing a regimen. Frank discussion with family member is critical, especially at the outset of therapy. DR-TB is life-threatening, and none of anti-tuberculotic drugs is absolutely contraindicated in children. Children who have received treatment for DR-TB have generally tolerated the second-line drugs well (13).

Although fluoroqinolones have been shown to retard cartilage development and degenerative changes in beagle puppies, experience with the use of fluoroquinolones has not demonstrated similar effects in humans. Therefore, the benefit of fluoroquinolones in treating DR-TB in children outweighs any risk. Additionally, ethionamide, PAS and cycloserine have been used effectively in children and are well tolerated (14).

In general, anti-tuberculotic drugs should be dosed according to the body weight. Regular monitoring of body weight (every month in neonates, later every 6 months) is therefore especially important in pediatric cases, with adjustment of doses as children gain weight. All drugs, including the fluoroquinolones, should be dosed at the higher part of the recommended ranges whenever possible, except ethambutol. Ethambutol should be dosed at 15.0 $\mathrm{g} / \mathrm{kg}$, and not at $25.0 \mathrm{mg} / \mathrm{kg}$ as sometimes used in adults with DR-TB; the reason is a worse and more difficult monitoring of optic neuritis in children (15).

In children who are not culture-positive initially, treatment failure is difficult to assess. Persistent abnormalities on chest X-rays do not necessarily signify a lack of improvement. In children, weight loss or, more commonly failure to gain weight adequately, is of particular concern and often one of the first (or only) signs of treatment failure. This is another key reason to monitor weight carefully in children. 


\section{The situation in Slovakia}

The incidence of tuberculosis is decreasing during last decades in Slovakia. However, despite continual decrease of overall incidence, the number of DR-TB is increasing continuously, with occurrence of mono-resistance (mostly to izoniazid) and poly-resistance (mostly to streptomycin and isoniazid). In 2011, one case o MDR-TB was diagnosed, with $M$. tuberculosis strain resistant to all first-line anti-tuberculotics, kanamycine, ethionamid and cycloserine (16). Compared to other countries in Eastern Europe, the incidence of MDR-TB in Slovakia is relatively small, similarly to Czech Republic (17). The results of older periodic surveys showed that more than $10 \%$ of new tuberculosis cases in former Soviet Union countries are MDR-TB (18). Although parts of Eastern Europe are clearly hotspots for MDR-TB, only 3\% of all the new tuberculosis cases that arise worldwide every year are estimated to be multidrug resistant. However, the frequency of MDR-TB among previously treated cases is higher (19).

Over the years 2010-2012, totally 47 children with TB were detected in Slovakia - only 16 cases were associated with positive results of microbiological cultivation (Fig. 1). In this pilot study, we have retrospectively analyzed all children sputum samples from children with microbiologically diagnosed TB. The classical bacteriological analysis (culture on solid eggsbased media) was used to confirm the $M$. tuberculosis infection and the proportion method was applied to test its susceptibility or resistance to mostly used antituberculotics. Three cases of resistant TB in children have been diagnosed in the National Reference Center for Mycobacteria (2010 - one case, 2012- two cases). In all three cases mono-resistance to isoniazid had been confirmed, which is the most common mono-resistance.

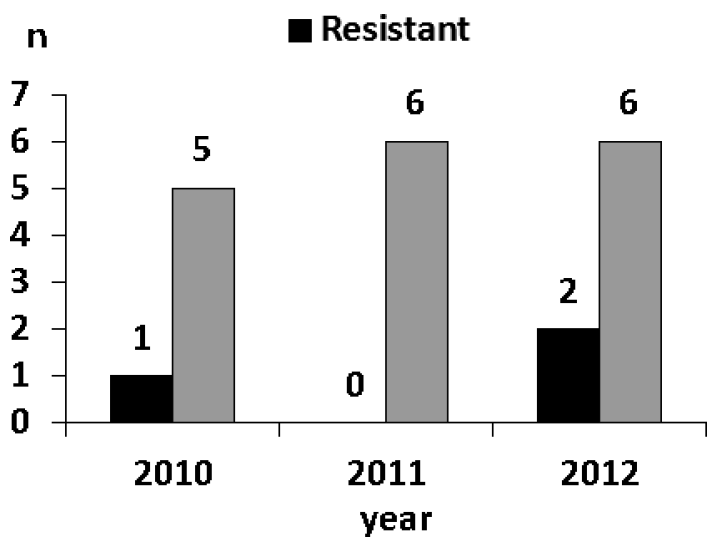

Fig. 1 Number of children with bacteriologically confirmed susceptible and resistant tuberculosis in years 20102012 in Slovakia.

All three children with confirmed resistance to isoniazid were treated at Children Institute of Tuberculosis and Respiratory Diseases in the Dolny Smokovec. At the same time, in the National Institute of Tuberculosis, Lung Diseases and Thoracic Surgery in Vyšné Hágy have been hospitalized relatives of these children. They have been diagnosed with identical monoresistance. Despite the fact that the number of included patients is limited, it confirms the theory that resistant tuberculosis in children is generally the primary one.

\section{CONCLUSION}

Resistance to anti-tuberculotic drugs in children exists also in Slovakia. Although currently it does not represent a serious problem, the globalization increases risks of its import, especially the more dangerous forms like MDR and XDR. Resistant tuberculosis is a diag- 
nostic and therapeutic problem not only in adults. Therefore, it is necessary to manage pediatric patients with suspected resistant TB in specialized institutions, with capabilities of the bacteriological quality diagnostics using the most advanced methods available. Furthermore, the proven resistance contacts must be taken into consideration during the diagnostic process.

\section{REFERENCES}

1. Skrahina A, Hurevich H, Zalutskaya A, Sahalchyk E, Astrauko A, van Gemert W, Hoffner S, Rusovich V. Zignol M. Alarming levels of drug-resistant tuberculosis in Belarus: results of a survey in Minsk. Eur Respir J 2012; 39: 1425-31.

2. Solovič I. Tuberkulóza, vybrané kapitoly. Vyšné Hágy, NÚTPCHaHCH 2008.

3. van Rie A, Warren R, Richardson M, Gie RP, Enarson DA, Beyers N, Van Helden PD. Classification of drugresistant tuberculosis in an epidemic area. Lancet 2000; 356 (9223): 22-5.

4. Rozborilová E. Tuberkulóza a mykobakteriózy. Bratislava, UK, 2009.

5. van der Werf MJ, Langendam MW, Huitric E, Manissero D.Multidrug resistance after inappropriate tuberculosis treatment: a meta-analysis. Eur Respir J 2012; 39 (6): 1511-9.

6. Cegielski P, Nunn P, Kurbatova EV, Weyer K, Dalton TL, Wares DF, et al. Challenges and controversies in defining totally drug-resistant tuberculosis. Emerg Infect Dis [Internet]. 2012 Nov [07.02.2013].

7. WHO. Guidelines for the programmatic management of drug-resistant tuberculosis: Emergency Update 2008. WHO/HTM/TB/2008.402. Geneva, Switzerland: WHO, 2008.

8. Cruz AT, Starke JR. Pediatric Tuberculosis. Pediatrics in Review 2010; 31:13-26.

9. Ván̆a J, Johanes R, Adamicová K, Žáček M. Zriedkavá pričina náhlej brušnej príhody. Slovenská chirurgia 2010; 7(1-2):12-4.

10. Jaramillo E. Guidelines for programmatic management of drug-resistant tuberculosis. Stop TB Initiative, WHO, 2008, p. 247.

11. Hopewell PC, Madhukar P, Maher D, Uplekar M, Raviglione MC. International Standards for Tuberculosis Care. Lancet Inf Dis 2006; 6(11): 710-25.

12. Drobac PC, Mukherjee JS, Joseph JK, MItnick C, Furin JJ, del Castillo H, Shin SS, Becerra MC. CommunityBased Therapy for Children With Multidrug-Resistant Tuberculosis. Pediatrics 2006; 117 (6): 2022-9.

13. Albanna AS, Menzies D. Drug-Resistant Tuberculosis: What are the Treatment Options? Drugs 2011; 71 (7): 815-25.

14. Al-Dabbagh M, Lapphra K, McGloin R, Inrig K, Schaaf HS, Marais BJ, Sauve L, Kitai I, Kollmann TR. Drugresistant tuberculosis: pediatric guidelines. Pediatr Infect Dis J 2011; 30 (6): 501-5.

15. Seddon JA, Hesseling AC, Marais BJ, Mcllleron H, Peloquin CA, Donald PR, Schaaf HS. Paediatric use of second-line anti-tuberculosis agents: a review. Tuberculosis (Edinb) 2012; 92 (1): 9-17.

16. Porvazník I, Mokrý J, Solovič I. Actual situation in resistance to anti-tuberculotics in Slovak Republic (In Slovak). In: Čalkovská A. (ed). Novinky v experimentálnej a klinickej medicíne. Zborník. JLFUK Martin, 2012: $152-9$.

17. Bartu V, Kopecka E, Havelkova M. Factors Associated with Multidrugresistant Tuberculosis: Comparison of Patients Born Inside and Outside of the Czech Republic. The Journal of International Medical Research 2010; 38: 1156-63.

18. WHO IUATALD. Anti-tuberculosis drug resistance in the world:third global report. Geneva: World Health Organization, 2004: 299.

19. Zignol M, Hosseini MS, Wright A, Lambregts-van Weezenbeek C, Nunn P, Watt CJ, Williams BG, Dye C. Global incidence of multidrug-resistant tuberculosis. J Infect Dis 2006; 194:479-85.

Received: October, 31, 2013

Accepted: November, 25, 2013 